\title{
Is There a Need to Alter the Timing of Anti-Müllerian Hormone Measurement During the Menstrual Cycle?
}

\author{
Muss der Zeitpunkt der Messung von Anti-Müller-Hormon \\ während des Menstruationszyklus geändert werden?
}

(두)(i) (ㄹㅇㅇㅛ

\author{
Authors \\ Umit Gorkem, Cihan Togrul
}

Affiliation

Hitit University Faculty of Medicine, Department of Obstetrics and Gynecology, Corum, Turkey

Key words

Anti-Müllerian hormone, AMH, fluctuation, ovarian reserve, variation, measurement

Schlüsselwörter

Anti-Müller-Hormon, AMH, Fluktuation, ovarielle Reserve, Variation, Messung

received 24.8.2018

revised 14.1.2019

accepted 23.1.2019

\section{Bibliography}

DOI https://doi.org/10.1055/a-0840-3817

Geburtsh Frauenheilk 2019; 79: 731-737 @ Georg Thieme

Verlag KG Stuttgart · New York | ISSN 0016-5751

Correspondence

Umit Gorkem

Hitit Universitesi Erol Olçok Eğitim ve Araştırma Hastanesi Kadın Hastalıkları ve Doğum Kliniği IVF Bölümü

İnönü Street, Çorum 19030, Turkey

drumitgorkem@hotmail.com

\section{ABSTRACT}

Introduction There are numerous conflicting studies which have addressed the question whether the measurement of anti-Müllerian hormone (AMH) concentrations should be done at a certain time during the menstrual cycle. We aimed to investigate $\mathrm{AMH}$ fluctuations during the follicular and luteal phases of the menstrual cycle and to determine whether $\mathrm{AMH}$ variations, if present, might influence the clinical utility of ovarian reserve markers.

Materials and Methods A total of 257 infertile women eligible for inclusion were categorized into three groups based on their total antral follicle count: 1 . hypo-response group
( $<7$ follicles, $n=66$ ), 2 . normo-response group (7-19 follicles, $n=98$ ), and 3. hyper-response group ( $>19$ follicles, $n=93$ ).

Results Mean follicular AMH levels were elevated compared to levels in the luteal phase in all response groups $(p<0.001)$. There were significant and strong positive correlations between follicular and luteal AMH levels in all response groups (Spearman's $r=0.822, r=0.836$, and $r=0.899$, respectively; $\mathrm{p}<0.001$ for all groups). Fisher's Z-test comparisons of these correlations in all response groups demonstrated that there was no statistically significant difference $(Z=0.277$, $Z=-1.001$, and $Z=-1.425$, respectively; $p<0.001$ ).

Conclusion We found that serum AMH levels in the follicular phase were higher than those in the luteal phase in all three response groups. In current practice, fluctuations in serum $\mathrm{AMH}$ concentrations are not large enough to alter the timing of $\mathrm{AMH}$ measurements during the menstrual cycle. The issue is important for the assessment of ovarian reserve in infertile women with $\mathrm{AMH}$ levels near to the cut-off value.

\section{ZUSAMMENFASSUNG}

Einleitung Es gibt zahlreiche widersprüchliche Studien, die sich der Frage widmen, ob die Messung des Anti-Müller-Hormon-(AMH-)Spiegels an einem bestimmten Zeitpunkt im Menstruationszyklus durchgeführt werden sollte. Ziel dieser Studie war es, Fluktuationen des Anti-Müller-Hormon-Spiegels während der Follikelphase und der Lutealphase des Menstruationszykluses zu messen, auch um zu bestimmen, ob Fluktuationen des AMH-Spiegels, falls es sie gibt, den klinischen Nutzen als Marker der ovariellen Reserve beeinflussen könnten.

Material und Methoden Insgesamt 257 unfruchtbare Frauen, welche die Einschlusskriterien erfüllten, wurden in die Studien eingeschlossen und in 3 Reaktionsgruppen eingeteilt. Die Einteilung beruhte auf der jeweiligen Gesamtzahl antraler Follikel, wie folgt: 1 . Hypo-Gruppe (<7 Follikel, $n=66)$, 2 . Normalgruppe (7-19 Follikel, $n=98)$, und 3. Hyper-Gruppe ( $>19$ Follikel, $\mathrm{n}=93$ ).

Ergebnisse Verglichen mit der Lutealphase war der durchschnittliche AMH-Spiegel während der Follikelphase in allen 3 Gruppen erhöht $(p<0,001)$. Es gab eine signifikante und 
starke positive Korrelation zwischen dem AMH-Spiegel in der Follikelphase und dem AMH-Spiegel in der Lutealphase bei allen Gruppen (Korrelationskoeffizient nach Spearman $r=0,822, r=0,836$ bzw. $r=0,899 ; p<0,001$ für alle Gruppen). Der Vergleich dieser Korrelationen mithilfe des Fisher-z-Tests zeigte, dass es in keiner der Gruppen einen statistisch signifikanten Unterschied gab $(z=0,277, \quad z=-1,001$ bzw. $z=-1,425 ; p<0,001)$.
Schlussfolgerung Es stellte sich heraus, dass in allen 3 Gruppen der AMH-Spiegel in der Follikelphase höher war als der AMH-Spiegel in der Lutealphase. Die Flukutationen des AMH-Spiegels sind jedoch nicht hoch genug, um den Zeitpunkt der AMH-Messung während des Menstruationszyklus in der aktuellen klinischen Praxis zu ändern. Dieses Thema ist aber für die Evaluierung der ovariellen Reserve von unfruchtbaren Frauen mit AMH-Spiegeln, die nahe beim Cut-off-Wert sind, von Bedeutung.

\section{Introduction}

A reliable assessment of ovarian reserve status is essential when designing strategies for individualized controlled ovarian stimulation, not only for poor- and hyper-responders, but also for women of more advanced age and women who want to delay their pregnancy for numerous reasons. Fertility preservation is an emerging field that encompasses a range of fertility therapies for women facing circumstances that threaten their future reproductive outcomes. Consequently, the assessment of ovarian reserve has become an important aspect of fertility preservation strategies [1, 2].

In the current body of literature, various markers of ovarian reserve have been described, including age, estradiol (E2), folliclestimulating hormone (FSH), inhibin $B$, antral follicle count (AFC), and anti-Müllerian hormone (AMH) levels [3-5]. Currently, $\mathrm{AMH}$ and AFC are thought to be efficient and equivalent predictors, especially in women at the extremes of ovarian reserve status [69]. In daily clinical practice, the choice of ovarian reserve marker depends on several variables, including the clinic's organization, the clinician's preference, and a number of specific patient characteristics.

Recently, AFC has been reported to be one of the most accepted predictors for evaluating ovarian reserve [10,11]. Many studies have demonstrated that an AFC $<7$ is associated with fewer retrieved oocytes [12] and lower pregnancy rates [13]. Moreover, an AFC value of more than 19 may indicate an excessive ovarian response to controlled ovarian stimulation and an increased likelihood of ovarian hyperstimulation syndrome [14].

$\mathrm{AMH}$ is a unique glycoprotein released by the granulosa cells of small growing follicles. AMH expression is initiated by the recruitment of primordial follicles; the highest level of $\mathrm{AMH}$ expression is observed in pre-antral and small antral follicles. During the FSHdependent stages of follicle growth and in atretic follicles, $\mathrm{AMH}$ is not secreted into the circulation [15]. Unlike FSH levels, AMH expression has only mild intra- and inter-cycle fluctuations [1618]. Although previous studies reported a low variability in $\mathrm{AMH}$ levels during the menstrual cycle [18-21], more recent studies reported a decrease in $\mathrm{AMH}$ levels in the luteal phase of menstruation $[26,27]$. Hence, in clinical practice, practitioners have asked whether the measurement of $\mathrm{AMH}$ concentrations in serum should be preferably carried out at a specific time in the menstrual cycle.

The present study aimed to investigate $\mathrm{AMH}$ fluctuations during the follicular and luteal phases of the menstrual cycle and to determine whether variations in AMH levels, if present, might influence the clinical utility of ovarian reserve markers.

\section{Materials and Methods}

\section{Study design}

This cross-sectional study was conducted at the Reproductive Endocrinology Department of Hitit University Hospital between 1 February 2015 and 20 December 2015. The ethics committee of Ankara Numune Hospital approved this project in accordance with the 2013 Declaration of Helsinki (20796219-724.087). After obtaining the informed consent of patients, women ranging in age from 18 to 38 were given a questionnaire to identify their eligibility for inclusion in the study.

Exclusion criteria were gestation, breastfeeding, premature ovarian insufficiency, current medication use, interventions and systemic diseases known to affect reproductive functions, hyperprolactinemia, ovarian surgery, hysterectomy and/or oophorectomy, endometriosis, ovarian masses, severe obesity (body mass in$\operatorname{dex}[\mathrm{BMI}] \geq 35 \mathrm{~kg} / \mathrm{m}^{2}$ ), and smoking. A level of midluteal progesterone $>3 \mathrm{ng} / \mathrm{dL}$ was taken in all participants to be an indicator of ovulation.

All participants underwent a physical examination, and weight, height and waist circumference (WC) measurements were obtained from all participating patients. Body mass index (BMI) was calculated by dividing the weight in kilograms by the height in meters squared. WC measurements were obtained at the level of the iliac process and the umbilicus, with the same scale used to assess abdominal obesity. During routine pelvic evaluation, AFC was evaluated using ultrasonography (Toshiba Xario 100, Toshiba Medical Systems Corporation, Nasu, Japan) with a 7.5-MHz vaginal transducer; ultrasonography was carried out by the same clinician on days 2-5 of the menstrual cycle.

A total of 257 infertile women eligible for inclusion were categorized into three groups, based on their total AFC, an ovarian response pattern marker, as follows:

1. hypo-response group ( $<7$ follicles, $n=66$ ),

2. normo-response group (7-19 follicles, $n=98)$, and

3. hyper-response group ( $>19$ follicles, $n=93$ ).

\section{Specimen collection and assays}

After an overnight fast, blood samples were drawn from the participants between the hours of 08:00 and 10:00 on days 2-5 of their menstrual cycle to obtain follicular AMH (F-AMH), E2 and 
- Table 1 Comparison of clinical and biochemical characteristics of all ovarian response groups.

\begin{tabular}{|c|c|c|c|c|}
\hline & \multicolumn{3}{|l|}{ Ovarian response groups } & \multirow[b]{2}{*}{$\mathbf{p}$} \\
\hline & $\begin{array}{l}\text { Hypo-responders } \\
\operatorname{AFC}<7(n=66,25.7 \%)\end{array}$ & $\begin{array}{l}\text { Normo-responders } \\
\text { AFC 7-19 }(n=98,38.1 \%)\end{array}$ & $\begin{array}{l}\text { Hyper-responders } \\
\text { AFC }>19(n=93,36.2 \%)\end{array}$ & \\
\hline Age (years) & $35.5( \pm 3.1)$ & $28.3( \pm 5.0)$ & $27.6( \pm 4.7)$ & $<0.001^{*}$ \\
\hline $\operatorname{BMI}\left(\mathrm{kg} / \mathrm{m}^{2}\right)$ & $26.3( \pm 4.1)$ & $26.4( \pm 5.5)$ & $26.0( \pm 4.9)$ & 0.879 \\
\hline$W C(\mathrm{~cm})$ & $90.9( \pm 9.5)$ & $89.0( \pm 12.2)$ & $90.0( \pm 15.5)$ & 0.738 \\
\hline Duration of infertility (weeks) & $52.7( \pm 56.4)$ & $45.3( \pm 42.3)$ & $39.4( \pm 36.2)$ & 0.318 \\
\hline $\mathrm{E} 2(\mathrm{pg} / \mathrm{mL})$ & $53.5( \pm 31.4)$ & $42.5( \pm 20.5)$ & $39.7( \pm 22.0)$ & 0.065 \\
\hline FSH (IU/L) & $9.0( \pm 2.7)$ & $6.8( \pm 1.2)$ & $6.3( \pm 2.0)$ & $<0.001^{*}$ \\
\hline F-AMH (ng/dL) & $1.3( \pm 1.7)$ & $3.4( \pm 1.8)$ & $7.3( \pm 4.6)$ & $<0.001^{*}$ \\
\hline L-AMH (ng/dL) & $1.1( \pm 1.2)$ & $2.63( \pm 1.63)$ & $5.95( \pm 3.54)$ & $<0.001^{*}$ \\
\hline AFC & $6.0( \pm 1.5)$ & $12.51( \pm 3.46)$ & $28.03( \pm 3.78)$ & $<0.001^{*}$ \\
\hline
\end{tabular}

FSH values. Blood samples were also drawn one week before the expected onset of menstruation to obtain luteal $\mathrm{AMH}(\mathrm{L}-\mathrm{AMH})$ values in the same menstrual cycle. The blood samples were left to clot completely at room temperature for 30 min before centrifugation at $1500 \times \mathrm{g}$ for $4 \mathrm{~min}$. The serum specimens for $\mathrm{E} 2$ and FSH were analyzed daily by electrochemiluminescence immunoassay (ECLIA) using an autoanalyzer (Cobas 6000, E 601 Roche Diagnostics $\mathrm{GmbH}$, Mannheim, Germany). The sera for both follicular and luteal $\mathrm{AMH}$ were frozen at $-20^{\circ} \mathrm{C}$ within $2 \mathrm{~h}$ for a maximum of one week. All assays of serum samples to measure $\mathrm{AMH}$ levels were also carried out according to a weekly schedule in accordance with the manufacturer's guidelines and using the $\mathrm{AMH}$ Gen II enzyme-linked immunosorbent assay (ELISA) from Beckman Coulter (Beckman Coulter, Co. Clare, Ireland).

\section{Statistical analysis}

All data were analyzed using SPSS (Statistical Package for the Social Sciences) version 21 (SPSS Inc., Chicago, IL, USA). Continuous variables were first evaluated using the Kolmogorov-Smirnov test for normality distribution. Because continuous variables were not normally distributed, non-parametric tests were used for statistical analysis. Descriptive data are given as mean ( \pm standard deviation) and figures (\%). Data from the three AFC groups were compared using one-way analysis of variance (ANOVA) with post-hoc analysis. Spearman's correlation was used to determine if there was any linear relationship between $\mathrm{AMH}$ levels and other study variables. The correlation coefficients were compared using Fisher's Z-test. A p-value $<0.05$ and a confidence interval of $95 \%$ were considered statistically significant.

\section{Results}

\section{Baseline clinical and biochemical characteristics}

A total of 257 infertile women were included in this study. The comparisons of clinical and biochemical characteristics of all ovarian response groups are presented in $>$ Table $\mathbf{1}$. Based on their AFC categorization, the mean age of the hypo-responder group was $35.5( \pm 3.1)$ years; the normo-responder and hyper-responder groups had mean ages of $28.3( \pm 5.0)$ and $27.6( \pm 4.7)$, respectively $(p<0.001)$. Characteristics such as BMI, WC, and duration of infertility were statistically similar for the hypo-, normo-, and hyperresponse groups $(p=0.879, p=0.738$, and $p=0.318$, respectively).

With regard to biochemical characteristics, there was no difference in mean E2 levels for all three groups ( $p=0.065)$. As could be expected, the hypo-responder group had a higher FSH concentration $(p<0.001)$ compared to the other ovarian response groups, and the mean AFC was higher in the hyper-responder group in comparison to the other ovarian response groups $(p<0.001)$. Mean follicular and luteal AMH levels were found to be elevated in hyper-responder women ( $p<0.001$, for all groups).

\section{$\mathrm{AMH}$ levels in the respective ovarian response groups}

Comparisons of serum AMH concentrations during the follicular and luteal phases of the menstrual cycle and comparisons between the three response groups are presented in $>$ Table 2 . Significant differences were found in the $\mathrm{F}-\mathrm{AMH}$ and $\mathrm{L}-\mathrm{AMH}$ levels of women in the hypo-, normo- and hyper-response groups $(p<0.001$, for all groups). The mean F-AMH levels in all response groups were elevated compared to the mean F-AMH levels in the luteal phase $(p<0.001)$. 
- Table 2 Comparison of AMH measurements obtained in the follicular and luteal phases in the ovarian response groups.

\begin{tabular}{|c|c|c|c|c|c|}
\hline & $\begin{array}{l}\text { All subjects } \\
(n=171,100 \%)\end{array}$ & $\begin{array}{l}\text { Hypo-responders } \\
\text { AFC }<7(n=66,25.7 \%)\end{array}$ & $\begin{array}{l}\text { Normo-responders } \\
\text { AFC } 7-19(n=98,38.1 \%)\end{array}$ & $\begin{array}{l}\text { Hyper-responders } \\
\text { AFC }>19(n=93,36.2 \%)\end{array}$ & p-value \\
\hline F-AMH & $4.3( \pm 3.9)$ & $1.3( \pm 1.7)$ & $3.4( \pm 1.8)$ & $7.3( \pm 4.6)$ & $<0.001^{*}$ \\
\hline L-AMH & $3.5( \pm 3.1)$ & $1.1( \pm 1.2)$ & $2.6( \pm 1.6)$ & $6.0( \pm 3.5)$ & $<0.001^{*}$ \\
\hline Spearman's correlation ( $r$ ) & 0.928 & 0.852 & 0.836 & 0.899 & \\
\hline $\mathrm{p}$-value & $<0.001^{*}$ & $<0.001^{*}$ & $<0.001^{*}$ & $<0.001^{*}$ & \\
\hline
\end{tabular}

\section{Correlations of biochemical parameters in the ovarian reserve groups}

- Table 3 shows the correlation matrix for the biochemical parameters of each ovarian response group. There were significant and strong positive correlations between follicular $\mathrm{AMH}$ levels and luteal AMH levels of women in the hypo-, normo-, and hyper-response groups (Spearman's $r=0.822, r=0.836$, and $r=0.899$, respectively; $p<0.001$ for all groups). However, as shown in > Table 4, Fisher's Z-test comparisons of these correlations in all response groups demonstrated that there was no statistically significant difference $(Z=0.277, Z=-1.001$, and $Z=-1.425$, respectively; $p<0.001$ for all groups). In other words, the differences in the correlation coefficients of all ovarian response groups were statistically similar for all ovarian response groups.

\section{Discussion}

Our study mainly focused on whether serum AMH levels exhibit any variability throughout the follicular and luteal phases of the menstrual cycle in infertile women with different ovarian response patterns and whether $\mathrm{AMH}$ variation, if present, might have an impact on clinical practice with regard to the timing of $\mathrm{AMH}$ measurement. Our evidence revealed that mean AMH concentrations in the follicular phase were markedly elevated compared to mean L-AMH concentrations in the hypo-, normo-, and hyper-response groups. F-AMH and L-AMH were also strongly and positively correlated in all three groups. There was no statistically significant difference with regard to correlation in all response groups.

As previously emphasized, the existing literature has provided no consistent information about intracyclic $\mathrm{AMH}$ variation. La Marca et al. [24] performed AMH measurements independently of the day of the menstrual cycle; in their study, they noted that serum AMH levels did not differ across the menstrual cycle. Other investigators reported similar findings $[18,19]$. Some researchers

- Table 3 Correlation matrix for the biochemical parameters of all ovarian response groups.

\begin{tabular}{|c|c|c|c|c|c|}
\hline Ovarian response groups & & F-AMH & L-AMH & E2 & FSH \\
\hline \multirow{4}{*}{$\begin{array}{l}\text { Hypo-responders } \\
\mathrm{AFC}<7(\mathrm{n}=66,25.7 \%)\end{array}$} & $\mathrm{F}-\mathrm{AMH}$ & 1.000 & & & \\
\hline & L-AMH & $0.852^{*}$ & 1.000 & & \\
\hline & E2 & 0.210 & 0.164 & 1.000 & \\
\hline & FSH & -0.241 & -0.258 & -0.229 & 1.000 \\
\hline \multirow{4}{*}{$\begin{array}{l}\text { Normo-responders } \\
\text { AFC 7-19 }(n=98,38.1 \%)\end{array}$} & F-AMH & 1.000 & & & \\
\hline & L-AMH & $0.836^{*}$ & 1.000 & & \\
\hline & E2 & -0.035 & -0.061 & 1.000 & \\
\hline & FSH & -0.020 & -0.155 & -0.130 & 1.000 \\
\hline \multirow{4}{*}{$\begin{array}{l}\text { Hyper-responders } \\
\text { AFC }>19(n=93,36.2 \%)\end{array}$} & $\mathrm{F}-\mathrm{AMH}$ & 1.000 & & & \\
\hline & L-AMH & $0.899^{*}$ & 1.000 & & \\
\hline & E2 & -0.210 & -0.202 & 1.000 & \\
\hline & FSH & 0.022 & 0.037 & -0.087 & 1.000 \\
\hline \multicolumn{6}{|c|}{$\begin{array}{l}\text { Values are shown as Spearman's correlation coefficients (r). F-AMH: follicular anti-Müllerian hormone; L-AMH: luteal anti-Müllerian hormone; E2: estradiol } \\
\text { FSH: follicular stimulating hormone; AFC: antral follicle count. }\end{array}$} \\
\hline
\end{tabular}


- Table 4 Comparisons of correlation coefficients between all ovarian response groups.

\begin{tabular}{|c|c|c|c|c|}
\hline & $\begin{array}{l}\text { Correlation } \\
\text { coefficients }\end{array}$ & $\begin{array}{l}\text { Comparison of hypo- } \\
\text { and normo-responders }\end{array}$ & $\begin{array}{l}\text { Comparison of hypo- } \\
\text { and hyper-responders }\end{array}$ & $\begin{array}{l}\text { Comparison of normo- } \\
\text { and hyper-responders }\end{array}$ \\
\hline Hypo-responders & $r=0,852^{*}$ & \multirow{6}{*}{$\begin{array}{l}Z=0.277 \\
p>0.01\end{array}$} & \multirow{6}{*}{$\begin{array}{l}Z=-1.001 \\
p>0.01\end{array}$} & \multirow{6}{*}{$\begin{array}{l}Z=-1.425 \\
p>0.01\end{array}$} \\
\hline $\operatorname{AFC}<7(n=66,25.7 \%)$ & $Z=1.26$ & & & \\
\hline Normo-responders & $r=0,836^{*}$ & & & \\
\hline $\operatorname{AFC} 7-19(n=98,38.1 \%)$ & $Z=1.21$ & & & \\
\hline Hyper-responders & $r=0,899^{*}$ & & & \\
\hline AFC $>19(n=93,36.2 \%)$ & $Z=1.47$ & & & \\
\hline
\end{tabular}

have thought that either no $\mathrm{AMH}$ variation occurs during the menstrual cycle or that the variation is minimal $[25,26]$. In contrast, we have concluded that $\mathrm{AMH}$ fluctuates greatly across the menstrual cycle.

Numerous studies have investigated intracyclic AMH variations during the menstrual cycle. Although there are discrepancies in previous studies with regard to the timing of serum AMH concentrations, extreme values during the menstrual cycle, the pattern of variation, and the statistical significance, some degree of variation in $\mathrm{AMH}$ levels between different phases of the menstrual cycle has been reported [26]. In other published studies, a peak $\mathrm{AMH}$ level was observed in the mid-follicular phase; $\mathrm{AMH}$ levels then started to decline prior to a rise in serum E2 and reached their nadir in the early luteal phase $[25,27]$. In a recent study by Randolph et al., a biphasic pattern with an elevation and depression in both the follicular and the luteal phases was found in healthy premenopausal women [28]. Others have reported that serum AMH rises steadily and then declines during the entire luteal phase in premenopausal women. Hadlow et al. also investigated $\mathrm{AMH}$ fluctuations in infertile women. In line with our results, the authors reported that the mean AMH concentration was significantly depressed in the luteal phase of menstruation [22].

In a study by Sowers et al. with a very small sample size $(n=20)$, serum AMH levels were shown to fluctuate throughout the menstrual cycle [23]. Women with low AMH levels had small fluctuations, while women with high $\mathrm{AMH}$ levels exhibited relatively high fluctuations throughout the menstrual cycle. The authors described the fluctuating AMH levels as "aging ovary" and "younger ovary" patterns [25]. The same younger ovary pattern was also reported by Wunder et al. [25]. In contrast, we did not observe that pattern of variation in our study. In fact, all ovarian response groups exhibited significant variations in $\mathrm{AMH}$ levels in different phases of the menstrual cycle.

The reliability of the findings reported in previous studies on AMH fluctuations may be influenced by inappropriate sample processing and storage. Therefore, those findings should be considered critically. Numerous studies in the existing literature have reported findings on $\mathrm{AMH}$ variability utilizing $\mathrm{AMH}$ samples frozen at $-80^{\circ} \mathrm{C}$. However, Kumar et al. reported only minimal variation in samples when frozen at $-20^{\circ} \mathrm{C}$ for a period of seven days [29].
The most significant fluctuations appeared to occur when entire blood samples were kept at room temperature for a long period of time. Some authors have proposed that the average variation between fresh samples and samples stored for 7 days at room temperature was nearly $4 \%$, and that it was $1 \%$ in frozen samples [29]. At present, the discrepancies in existing studies may be explained by variations in serum sample collection, processing and storage [30]. Consequently, our study was done using an optimal methodology based on current evidence.

La Marca et al. published a review on AMH variations in normal women [16]. The authors stated that fluctuations in AMH levels throughout the menstrual cycle appear to be random and minor, and that $\mathrm{AMH}$ can be measured independently of the cycle phase. They also criticized a study by Hadlow et al., declaring that the study was based on a very small group of subjects $(n=12)[26]$. However, our study was conducted with a greater number of participants $(n=257)$. We also demonstrated a substantial fluctuation in AMH levels across the menstrual cycle in contrast to the review by La Marca et al [16]. It appears that AMH fluctuations are similarly clinically relevant for women with all types of ovarian response.

While real ovarian reserve does not vary throughout a natural cycle or between consecutive cycles of menstruation, the serum $\mathrm{AMH}$ level fluctuates, presumably due to biological variations and atypical $\mathrm{AMH}$ isoforms [31]. AMH that may be partially responsive to gonadotropins may also contribute to a variety of biological variations [32]. It has also been reported that gonadotropins may participate in stimulating the gonadotropin-dependent follicles and the AMH level [33]. Depmann et al. stated that variations in peripheral AMH levels throughout the menstrual cycle occur in parallel with AFC variations. This implies that intracyclic $\mathrm{AMH}$ variations may be due to changes in the number of antral follicles [34].

One strength of this study is that the study population consisted of infertile women, because the assessment of ovarian reserve is considered to be essential for predicting controlled ovarian stimulation in infertile women. Another strength is that a relatively large number of participants were included in the study. A major limitation of the study is the limited number of AMH measurements obtained throughout the menstrual cycle (only two measurements). 
In conclusion, our study revealed significant fluctuations in serum $\mathrm{AMH}$ levels between the follicular and luteal phases of the menstrual cycle. Serum AMH levels in the follicular phase were higher than those in the luteal phase in infertile women with hypo-, normo-, and hyper-response patterns. However, these $\mathrm{AMH}$ fluctuations were not statistically significant, so it was not possible to propose an optimal time for $\mathrm{AMH}$ measurement. The fluctuations in serum AMH concentrations observed in our study were not large enough to modify the timing of AMH measurement during the menstrual cycle in current clinical practice. The statistically significant changes during the menstrual cycle support the need for a greater understanding of potential $\mathrm{AMH}$ changes in normal follicles. Most importantly, the issue may play a critical role in the assessment of ovarian reserve in infertile women with an AMH level that is near the cut-off value. Thus, further largescale prospective studies and meta-analyses are warranted to determine the optimal time for $\mathrm{AMH}$ measurement.

\section{Acknowledgements}

The authors would like acknowledge the contributions of the staff of the Reproductive Endocrinology Unit of Hitit University.

Conflict of Interest

The authors declare that they have no conflict of interest.

References

[1] Dittrich R, Kliesch S, Schüring A et al. Fertility Preservation for Patients with Malignant Disease. Guideline of the DGGG, DGU and DGRM (S2 kLevel, AWMF Registry No. 015/082, November 2017) - Recommendations and Statements for Girls and Women. Geburtsh Frauenheilk 2018; 78: $567-584$

[2] Guenther V, Alkatout I, Junkers W et al. Fertility Preservation in Female Patients with Breast Cancer - a Current Overview. Geburtsh Frauenheilk 2017; 77: 1088-1094

[3] Broer SL, Mol BW, Hendriks D et al. The role of anti-Mullerian hormone in prediction of outcome after IVF: comparison with the antral follicle count. Fertil Steril 2009; 91: 705-714

[4] Broekmans FJ, de Ziegler D, Howles CM et al. The antral follicle count: practical recommendations for better standardization. Fertil Steril 2010; 94: 1044-1051

[5] Iliodromiti S, Anderson RA, Nelson SM. Technical and performance characteristics of anti-Müllerian hormone and antral follicle count as biomarkers of ovarian response. Hum Reprod Update 2015; 21: 698-710

[6] Broer SL, Dólleman M, Opmeer BC et al. AMH and AFC as predictors of excessive response in controlled ovarian hyperstimulation: a meta-analysis. Hum Reprod Update 2011; 17: 46-54

[7] Broer SL, Dólleman M, van Disseldorp J et al.; IPD-EXPORT Study Group. Prediction of an excessive response in in vitro fertilization from patient characteristics and ovarian reserve tests and comparison in subgroups: an individual patient data meta-analysis. Fertil Steril 2013; 100: 420429.e7

[8] La Marca A, Sunkara SK. Individualization of controlled ovarian stimulation in IVF using ovarian reserve markers: from theory to practice. Hum Reprod Update 2014; 20: 124-140

[9] Fleming R, Seifer DB, Frattarelli JL et al. Assessing ovarian response: antral follicle count versus anti-Mullerian hormone. Reprod Biomed Online 2015; 31: 486-496
[10] Amanvermez R, Tosun M. An Update on ovarian aging and ovarian reserve tests. Int J Fertil Steril 2016; 9: 411-415

[11] $\mathrm{Ng} \mathrm{EH}$, Tang OS, Ho PC. The significance of the number of antral follicles prior to stimulation in predicting ovarian responses in an IVF programme. Hum Reprod 2000; 15: 1937-1942

[12] Ferraretti AP, La Marca A, Fauser BC et al. ESHRE consensus on the definition of 'poor response' to ovarian stimulation for in vitro fertilization: the Bologna criteria. Hum Reprod 2011; 26: 1616-1624

[13] Coelho Neto MA, Martins WP, Lima ML et al. Ovarian response is a better predictor of clinical pregnancy rate following embryo transfer than is thin endometrium or presence of an endometrioma. Ultrasound Obstet Gynecol 2015; 46: 501-505

[14] Kollmann M, Martins WP, Raine-Fenning N. Examining the ovaries by ultrasound for diagnosing hyperandrogenic anovulation: updating the threshold for newer machines. Fertil Steril 2014; 101: e25

[15] Jeppesen JV, Anderson RA, Kelsey TW et al. Which follicles make the most anti-Mullerian hormone in humans? Evidence for an abrupt decline in $\mathrm{AMH}$ production at the time of follicle selection. Mol Hum Reprod 2013; 19: 519-527

[16] La Marca A, Grisendi V, Griesinger G. How much does AMH really vary in normal women? Int J Endocrinol 2013; 2013: 959487

[17] La Marca A, Sighinolfi G, Radi D et al. Anti-Müllerian hormone (AMH) as a predictive marker in assisted reproductive technology (ART). Hum Reprod Update 2010; 16: 13-30

[18] Hehenkamp WJ, Looman CW, Themmen AP et al. Anti-Müllerian hormone levels in the spontaneous menstrual cycle do not show substantial fluctuation. J Clin Endocrinol Metab 2006; 91: 4057-4063

[19] Tsepelidis S, Devreker F, Demeestere I et al. Stable serum levels of antiMüllerian hormone during the menstrual cycle: a prospective study in normoovulatory women. Hum Reprod 2007; 22: 1837-1840

[20] van Disseldorp J, Lambalk CB, Kwee J et al. Comparison of inter- and intra-cycle variability of anti-Mullerian hormone and antral follicle counts. Hum Reprod 2010; 25: 221-227

[21] La Marca A, Giulini S, Tirelli A et al. Antimullerian hormone measurement on any day of the menstrual cycle strongly predicts ovarian response in assisted reproductive technology. Hum Reprod 2007; 22: 766-771

[22] Hadlow N, Longhurst K, McClements A et al. Variation in antimüllerian hormone concentration during the menstrual cycle may change the clinical classification of the ovarian response. Fertil Steril 2013; 99: 17911797

[23] Sowers M, McConnell D, Gast K et al. Anti-Müllerian hormone and inhibin B variability during normal menstrual cycles. Fertil Steril 2010; 94: 14821486

[24] La Marca A, Spada E, Grisendi V et al. Normal serum anti-Müllerian hormone levels in the general female population and the relationship with reproductive history. Eur J Obstet Gynecol Reprod Biol 2012; 163: 180184

[25] Wunder DM, Bersinger NA, Yared M et al. Statistically significant changes of antimüllerian hormone and inhibin levels during the physiologic menstrual cycle in reproductive age women. Fertil Steril 2008; 89: 927-933

[26] Weenen C, Laven JS, Von Bergh AR et al. Anti-Müllerian hormone expression pattern in the human ovary: potential implications for initial and cyclic follicle recruitment. Mol Hum Reprod 2004; 10: 77-83

[27] Cook CL, Siow Y, Taylor S et al. Serum müllerian-inhibiting substance levels during normal menstrual cycles. Fertil Steril 2000; 73: 859-861

[28] Randolph JF, Harlow SD, Helmuth ME et al. Updated assays for inhibin B and $\mathrm{AMH}$ provide evidence for regular episodic secretion of inhibin $\mathrm{B}$ but not $\mathrm{AMH}$ in the follicular phase of the normal menstrual cycle. Hum Reprod 2014; 29: 592-600

[29] Kumar A, Kalra B, Patel A et al. Development of a second generation antiMullerian hormone (AMH) ELISA. J Immunol Methods 2010; 362: 51-59 
[30] Rustamov O, Smith A, Roberts SA et al. Anti-Mullerian hormone: poor assay reproducibility in a large cohort of subjects suggests sample instability. Hum Reprod 2012; 27: 3085-3091

[31] Robertson DM, Kumar A, Kalra B et al. Detection of serum antimüllerian hormone in women approaching menopause using sensitive antinüllerian hormone enzyme-linked immunosorbent assays. Menopause 2014; 12: $1277-1286$

[32] Hagen CP, Sørensen K, Anderson RA et al. Serum levels of antimüllerian hormone in early maturing girls before, during, and after suppression with GnRH agonist. Fertil Steril 2012; 98: 1326-1330
[33] Tran ND, Cedars MI, Rosen MP. The role of anti-mullerian hormone $(\mathrm{AMH})$ in assessing ovarian reserve. J Clin Endocrinol Metab 2011; 96: 3609-3614

[34] Depmann M, van Disseldorp J, Broer SL et al. Fluctuations in anti-Müllerian hormone levels throughout the menstrual cycle parallel fluctuations in the antral follicle count: a cohort study. Acta Obstet Gynecol Scand 2016; 95: 820-828 